\title{
Endoscopic Transmural Resection of a Neuroendocrine Tumor of the Appendix
}

\author{
Joana Castela ${ }^{a} \quad$ Daniela Vinha Pereirab $^{b}$ Susana Mão-de-Ferro ${ }^{a}$ \\ a Department of Gastroenterology, Instituto Português de Oncolologia de Lisboa Francisco Gentil, E.P.E., \\ Lisbon, Portugal; 'b Department of Pathology, Instituto Português de Oncolologia de Lisboa Francisco Gentil, E.P.E., \\ Lisbon, Portugal
}

\section{Keywords}

Full-thickness resection · Neuroendocrine tumor $\cdot$ Appendix

\section{Resseção endoscópica transmural de tumor neuroendócrino do apêndice}

\section{Palavras Chave}

Resseção transmural · Tumor neuroendócrino · Apêndice
A 51-year-old female patient with no relevant past medical history underwent colonoscopy for investigation of iron-deficiency anemia. Colonoscopy revealed a yellowish subepithelial lesion located in the appendix, 15 $\mathrm{mm}$ in size (Fig. 1). Biopsies showed a well-differentiated neuroendocrine tumor (NET G1). Additionally, the patient underwent a thoracic-abdominal-pelvic computed tomography $(\mathrm{CT})$ scan and Octreoscan ${ }^{\circledR}$, showing no lymph node involvement or distant metastases. The patient was referred to our center for transmural endoscop-
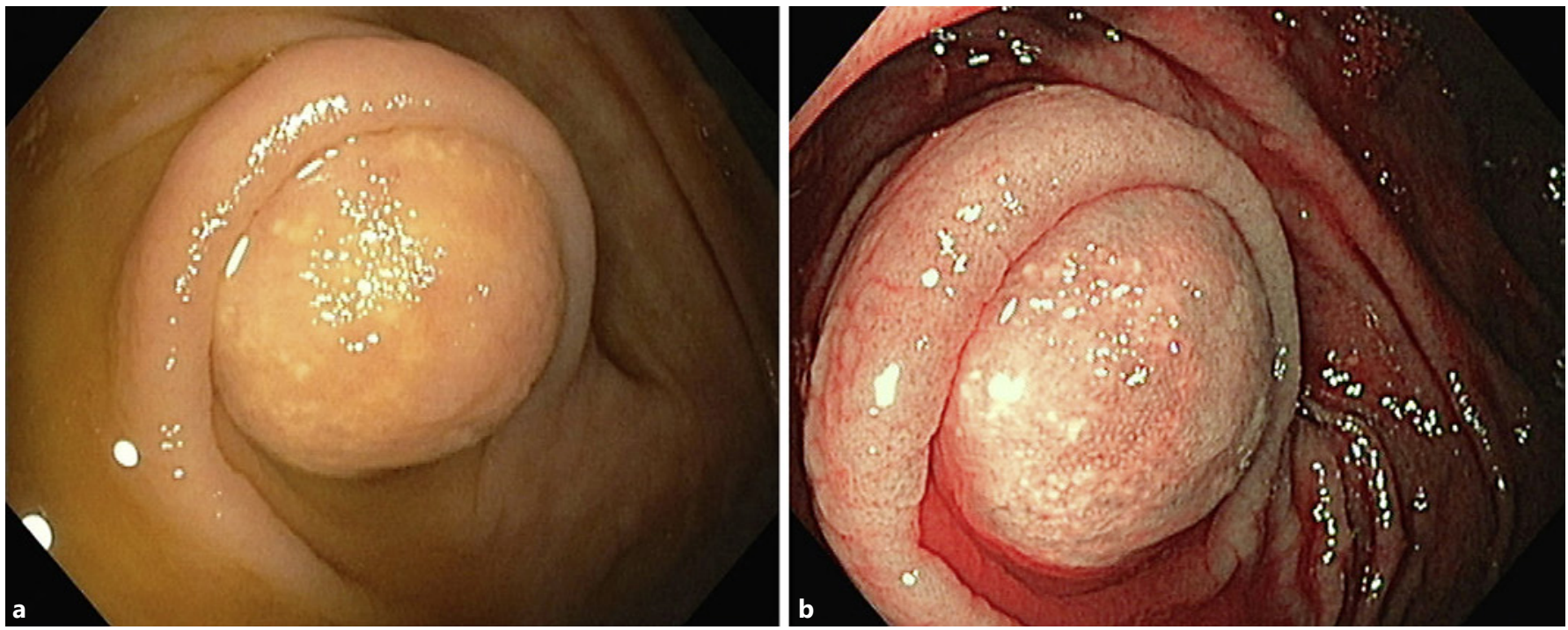

Fig. 1. a Subepithelial lesion of the appendix in white light. b Narrow-band imaging mode.

\section{KARGER}

E-Mail karger@karger.com www.karger.com/pjg
(C) 2019 Sociedade Portuguesa de Gastrenterologia Published by S. Karger AG, Basel

Karger

0 pen access

This article is licensed under the Creative Commons AttributionNonCommercial-NoDerivatives 4.0 International License (CC BYNC-ND) (http://www.karger.com/Services/OpenAccessLicense). Usage and distribution for commercial purposes as well as any distribution of modified material requires written permission.
Joana Castela

Department of Gastroenterology

Instituto Português de Oncologia de Lisboa Francisco Gentil, E.P.E.

Rua Prof. Lima Basto, PT-1099-023 Lisbon (Portugal)

E-Mail joanarocastela@gmail.com 

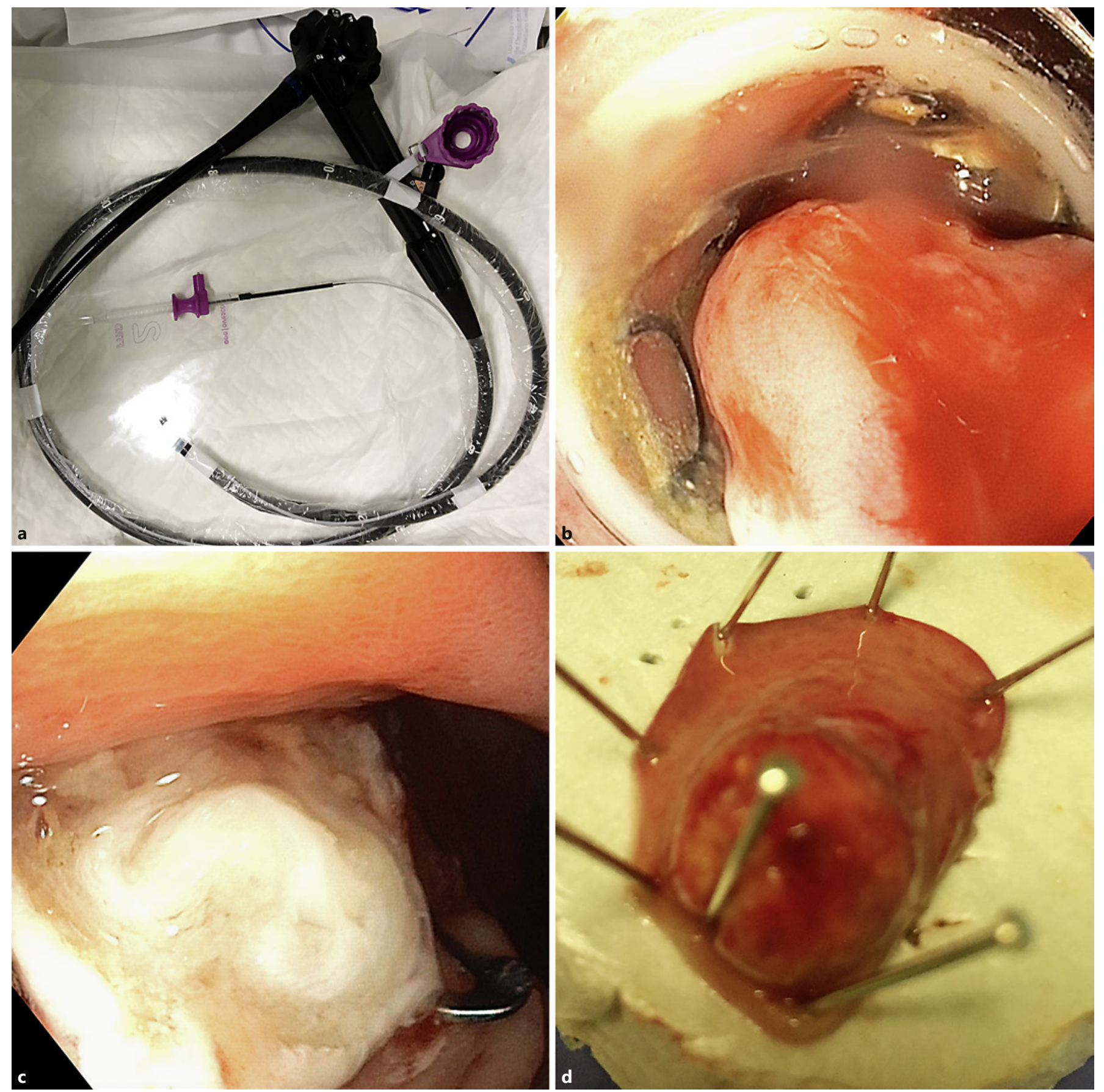

Fig. 2. a Full-thickness resection device mounted on a standard colonoscope. $\mathbf{b}$ The subepithelial lesion being pulled into the cap with the grasper. c Final result after resection of the NET with the OTSC securing the integrity of the colon wall. $\mathbf{d}$ The final resection specimen.

ic resection, using the full-thickness resection device $\left(\right.$ FTRD $^{\circledR}$; Ovesco Endoscopy AG). The FTRD is an overthe-scope system mounted on a standard colonoscope, composed of a plastic cap with a modified over-the-scope clip (OTSC ${ }^{\circledR}$; Ovesco Endoscopy AG), a preloaded snare $(13 \mathrm{~mm})$ that runs along the outer surface of the colonoscope under a plastic sheath and a grasper, used in the working channel. The procedure was performed under 


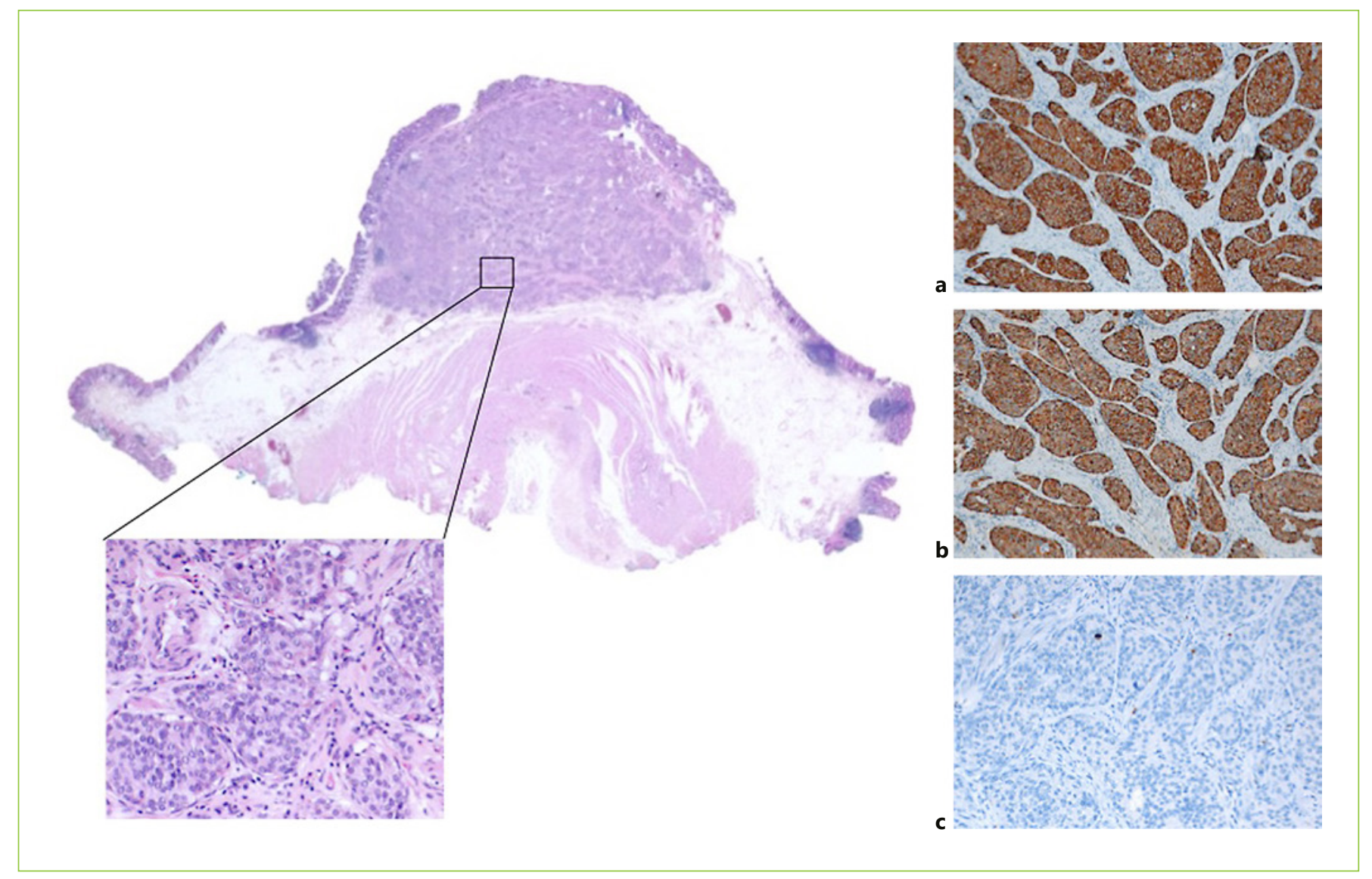

Fig. 3. Histology of the resected specimen. Well-differentiated neuroendocrine tumor with an insular growth pattern, composed of uniform cells with "salt-and-pepper" chromatin, scant nuclear pleomorphism, and no mitosis (H\&E; inset). a Synaptophysin. b Chromogranin A. c Ki67 = 1\%.

anesthesiologist-administered propofol deep sedation, with periprocedural administration of intravenous cefazoline and metronidazole. After identification and marking of the margins of the lesion, the FTRD was mounted on the colonoscope (CF-H190 Evis Exera III Videocolonoscope ${ }^{\circledR}$; Olympus Europe) (Fig. 2a). The lesion was then slowly pulled into the cap with the grasper, followed by OTSC deployment and excision of the pseudopolyp created by the OTSC with the preloaded snare (settings: Cut 1, Level 120, ESG-100, Olympus ${ }^{\circledR}$ ). The specimen was recovered and sent pinned on styrofoam for histopathological analysis. The resection site was reevaluated, showing no residual lesion (Fig. 2b). The patient was under prophylactic oral antibiotics for 7 days after the procedure. There were no early or delayed adverse events. The resection specimen consisted of a fullthickness wall colonic fragment measuring $28 \times 18 \mathrm{~mm}$, centered by a $13-\mathrm{mm}$ yellow submucosal nodule. The his- tology showed a NET G1 (0 mitosis/10 high-power field, Ki67 1\%) with infiltration of the subserosa ( $<1 \mathrm{~mm})$, no lymphovascular or perineural invasion, and negative lateral and deep margins (pT1b according to the UICC/ AJCC classification and pT2 according to the ENETS guidelines) (Fig. 3). After the procedure, the patient underwent a ${ }^{68} \mathrm{Ga}$-DOTA-NOC positron emission tomography/CT revealing no active disease. The case was discussed in the multidisciplinary board of neuroendocrine tumors, and surveillance with chromogranin A and an abdominal-pelvic CT scan was proposed. Currently, after 1 year of follow-up, there is no evidence of recurrence or distant metastases.

Appendiceal neuroendocrine tumors are frequently incidental findings in the appendectomy specimen. Usually, appendectomy is curative for small appendiceal NET $(<2 \mathrm{~cm})$, with excellent prognosis [1]. The FTRD is an endoscopic technique that allows a single-step transmu- 
ral resection of the colorectal lesions with previous application of OTSC that secures postprocedural integrity of the colonic wall. This technique is particularly useful for the treatment of lesions at difficult anatomic locations or with a high risk of complications (e.g., appendix), as well as subepithelial lesions up to $2-3 \mathrm{~cm}$ [2]. The FTRD may be a minimally invasive alternative to surgery, for selected patients, with excellent technical and safety results [3-5].

\section{Statement of Ethics}

The authors declare that no experiments on humans or animals were performed for this study. The authors declare that no patient data appear in this article.

\section{Disclosure Statement}

The authors declare that they have no conflicts of interest to disclose.

\section{Author Contributions}

Joana Castela is responsible for the preparation and writing of the manuscript; Daniela Vinha Pereira is responsible for the histological analysis and critical revision of the manuscript; and Susana Mão-de-Ferro executed the full-thickness resection procedure and is responsible for the critical revision of the manuscript.

\section{References}

1 Pape UF, Niederle B, Costa F, Gross D, Kelestimur F, Kianmanesh R, et al.; Vienna Consensus Conference participants. ENETS Consensus Guidelines for Neuroendocrine Neoplasms of the Appendix (Excluding Goblet Cell Carcinomas). Neuroendocrinology. 2016; 103(2):144-52.
2 Schmidt A, Bauerfeind P, Gubler C, Damm M, Bauder M, Caca K. Endoscopic full-thickness resection in the colorectum with a novel over-the-scope device: first experience. Endoscopy. 2015 Aug;47(8):719-25.

3 Schmidt A, Beyna T, Schumacher B, Meining A, Richter-Schrag HJ, Messmann $\mathrm{H}$, et al. Colonoscopic full-thickness resection using an over-the-scope device: a prospective multicentre study in various indications. Gut. 2018 Jul;67(7):1280-9.
4 Mão de-Ferro S, Castela J, Pereira D, Chaves P, Dias Pereira A. Endoscopic Fullthickness resection of colorectal lesions with the new FTRD system: single-center experience. GE Port J Gastroenterol. DOI: 10.1159/000493808.

5 Gomes ACR, Pinho R. Now, more than ever before, colonoscopy is a therapeutic procedure. GE Port J Gastroenterol. DOI: 10.1159/ 000494845 . 